\title{
DESAFIOS DAS EPISTEMOLOGIAS DECOLONIAIS E DO PARAdigMA ECOLÓgico PARA OS ESTUdos de RELIGIÃo
}

\author{
CHALLENGES OF DECOLONIAL EPISTEMOLOGIES AND THE ECOLOGICAL \\ PARADIGM FOR RELIGIOUS STUDIES
}

Paulo Agostinho Nogueira Baptista*

\begin{abstract}
RESUMO
Este artigo foi produzido no contexto do V Colóquio do Grupo de Pesquisa Religião e Cultura, do Programa de Pós-graduação em Ciências da Religião da PUC Minas, em outubro de 2017, que tratou do tema "A epistemologia das Ciências da Religião: pressupostos, questões e desafios". Discutiu-se numa das mesas-redondas, os desafios das "Epistemologia póscoloniais e os Estudos de Religião". A partir de pesquisa bibliográfica, este texto começa por tratar de questões básicas da epistemologia e a seguir apresenta, de forma panorâmica, o paradigma ecológico e as origens e ideias principais das teorias críticas pós-coloniais: o pensamento pós-colonial, os estudos subalternos, o pensamento descolonial e decolonial. As conclusões apontam que os Estudos de Religião têm muito a ganhar com essas epistemologias críticas e podem exercitar de modo criativo formas diversificadas e coletivas de fazer ciência, enfrentando, através da qualidade de suas produções, a desconfiança que outras áreas têm sobre as "Ciências da Religião". E, por ser multidisciplinar e estar em processo de construção epistemológica, devem entrar no debate duro da teoria da ciência. E, pela própria natureza de sua área, deve considerar o diálogo com os saberes religiosos, reconhecendo-lhes a dignidade de conhecimento, contribuindo para ecologizar e descolonizar ciências e saberes.
\end{abstract}

Palavras-chave: Epistemologias pós-coloniais. Decolonialidade. Paradigma ecológico. Estudos de Religião. Religião.

\section{ABSTRACT}

This article was produced within the context of the Fifth Colloquium of the Research Group on Religion and Culture of the Graduate Program in Religion Studies of PUC Minas, in October 2017, which dealt with the theme "The epistemology of the Sciences of Religion: assumptions, issues and challenges". One of the roundtables discussed the challenges of "postcolonial epistemology and religion studies". Based on bibliographical research, this text begins by addressing basic questions of epistemology and then presents, in a panoramic way, the ecological paradigm and the main origins and ideas of postcolonial critical theories: postcolonial thought, subaltern studies, decolonial and descolonial thinking. The conclusions indicate that Religion Studies have much to gain from these critical epistemologies and can exercise, in a creative way, diversified and collective ways of doing science, facing, through the quality of their productions, the distrust that other areas have about the "Sciences of Religion". Moreover, because this area of knowledge is multidisciplinary and in the process of an epistemological construction, it should be inserted in the hard debate of the theory of science. Finally, due to the very nature of this area, a dialogue with religious knowledge should be considered, recognizing the dignity of knowledge, thus contributing to the process of "greening up" as well as decolonizing sciences and knowledge.

\footnotetext{
* Doutor em Ciência da Religião Universidade Federal de Juiz de Fora, pós-doutor em Demografia (CEDEPLAR/Universidade Federal de Minas Gerais). Docente no Programa de Pós-graduação em Ciências da Religião da Pontifícia Universidade Católica de Minas Gerais. E-mail: pagostin@pucminas.br
}

INTERAÇõES, Belo Horizonte, Brasil, v. 13. n. 23, p.94-114, jan./jul.2018 ISSN 1983-2478 
Keywords: Postcolonial Epistemologies, Decoloniality, Ecological Paradigm, Religious Studies, Religion.

Você já passou por mim E nem olhou pra mim Você já passou por mim E nem olhou pra mim

Acha que eu não chamo atenção Engana o seu coração Acha que eu não chamo atenção

Não tem cor, não tem cara

Começou, não vai parar Coração vai disparar, não tem como dedurar Ninguém viu, ninguém viu, ninguém acha você Invisível, invisível, ninguém acha você

Há maneiras de ver, maneira de ser Maneira de crer, maneira de ver Cara-metade, cara-metade, quero te ver na cidade

Todo munda busca, ninguém acha você A cidade assusta, mas vai amanhecer

(Invisível, 2017 - BaianaSystem: Roberto Barreto, Marcelo Seko, Russo Passapusso)

\section{INTRODUÇÃO}

O debate epistemológico continua aberto e ao longo da história da filosofia da ciência recebeu contribuições importantes, para citar alguns, como de Carnap, Popper, Kuhn, Lakatos e tantas e tantos pesquisadores e centros de pesquisa. As Ciências da Religião, ou seus nomes derivativos desse campo de conhecimento, como os Estudos de Religião, têm um percurso significativo a fazer sobre esse debate, ainda mais se concebidos a partir de uma epistemologia plural. Se houve a caminhada desses estudos em espaços acadêmicos do primeiro mundo, como na Alemanha e Estados Unidos da América, pelas plagas e territorialidades dos outros mundos habitados e excluídos dos centros do saber, como América Latina, África e Ásia, os desafios são enormes.

Nesse sentido, o objetivo deste artigo é trazer alguns elementos que possam contribuir para essa discussão. A partir de levantamento e pesquisa bibliográfica, 
considerou-se necessário iniciar com algumas noções elementares sobre epistemologia. Assim, autores do campo dos Estudos da Religião, como Mircea Eliade, foram abordados, mesmo que de forma breve, mas significativa, através de contribuição teórica sobre um princípio epistemológico. Ainda refletindo sobre bases epistemológicas, o pensamento de Karl Popper se fez presente, assim como a discussão sobre conceito de paradigma de Thomas Kuhn.

No segundo momento do artigo são apresentadas as epistemologias críticas pós-coloniais, assim com o paradigma ecológico. Esse horizonte conceitual e histórico será importante para, no final, discutir sobre os desafios que essas epistemologias trazem para os Estudos de Religião. Mesmo que seja uma visão panorâmica, no espaço de um artigo, algumas referências podem ajudar no aprofundamento e discussão dessas questões.

A parte final do texto mostra que há proximidades entre as epistemologias apresentadas e que suas contribuições são fundamentais para fazer avançar os Estudos de Religião, como forma criativa de fazer ciência, especialmente no diálogo com culturas, tradições religiosas e sociedades, reconhecendo-lhes a dignidade de conhecimento, produzindo um processo de descolonização dos saberes e de sua integração ecológica.

\section{NOÇÕES ELEMENTARES SOBRE ALGUMAS BASES EPISTEMOLÓGICAS}

Nas aulas de graduação em Filosofia, geralmente em Teoria do Conhecimento ou Filosofia da Ciência, se aprende questões fundamentais para a formação filosófica e a compreensão do problema epistemológico. As ideias são ferramentas e andaimes que ajudam a pensar. Num livro de Mircea Eliade de 1940, Tratado de história das religiões (1993), no prefácio, há uma reflexão muito significativa, a partir de Henri Poincaré. Eliade apresenta um princípio epistemológico fundamental: "é a escala que cria o fenômeno" (ELIADE, 1993, p. 1). Esse princípio irá ser útil para as discussões que serão desenvolvidas à frente.

Outra aprendizagem epistemológica importante, a partir de Hilton Japiassú, é aquela que desmascara o mito da neutralidade e da objetividade científicas (JAPIASSÚ, 1975). A ciência é uma construção, uma luta em busca da verdade, e 
estão em jogo diversos interesses, incluindo a subjetividade do pesquisador. Mas essa visão já era defendida, desde 1935, por Karl Popper:

O velho ideal científico de episteme - do conhecimento absolutamente certo, demonstrável - mostrou não passar de um ídolo'. A exigência de objetividade científica torna inevitável que todo enunciado científico permaneça provisório para sempre [...]. Com a queda do ídolo da certeza, tomba uma das defesas do obscurantismo que barra o caminho do avanço da ciência. Com efeito, a idolatria desse ídolo afeta não apenas a temeridade de nossas questões, mas também o rigor e a integridade de nossos testes. A visão errônea da ciência se trai a si mesma na ânsia de estar correta, pois não é a posse do conhecimento, da verdade irrefutável, que faz o homem de ciência - o que o faz é a persistente e arrojada procura crítica da verdade. (POPPER, 1972, p. 308).

Reagindo ao princípio da verificabilidade de Carnap e do Círculo de Viena, Popper, em seu livro “A Lógica da Pesquisa Científica” (1935), mostrava que a ciência descobre ideias novas através do processo de falsificação, isto é, questionando antigas afirmações tidas como certezas:

só reconhecerei um sistema como empírico ou científico se ele for passível de comprovação pela experiência. Essas considerações sugerem que deve ser tomado como critério de demarcação, não a verificabilidade, mas a falsificabilidade do sistema. Em outras palavras, não exigirei que um sistema científico seja suscetível de ser dado como válido, de uma vez por todas, em sentido positivo; exigirei, porém, que sua forma lógica seja tal que se torne possível validá- lo através de recurso a provas empíricas, em sentido negativo: deve ser possível refutar, pela experiência, um sistema científico empírico. (POPPER, 1972, p. 42).

Tratando dessa questão, numa discussão sobre a epistemologia teológica, Hans Küng, reafirma essa tese de Popper dizendo que "não é pela verificação, mas por 'falsificação', ou seja, por refutação que se chega a novas hipóteses e teorias científicas. (KÜNG, 1999, p. 157).

Em que pese as críticas à visão de Popper (KUHN, 1962; LAKATOS, 1969; OLIVEIRA, 1982; ARAÚJO, 1996) e a algumas mudanças que ele realizou em suas teorias (POPPER, 1963), deve-se guardar para a discussão das questões deste texto essa ideia que a ciência é um processo e convive com mudança constante, ou como afirma o filósofo Stephen Toulmin (1978, p. 130), descontinuidades teóricas na ciência encobrem continuidades básicas e metodológicas mais profundas.

E outra concepção fundamental nesse debate emerge com o pensamento de Thomas Kuhn e é necessário apresenta-lo de forma mais ampla. Foi a partir das 
críticas às posições epistemológicas acima, na década de 1960, e em torno da discussão sobre a revolução científica, que teve lugar especialmente na Física, que Thomas Kuhn, físico e historiador da ciência, em seu livro "A estrutura das revoluções científicas” (1962), formula a ideia de que tais transformações nascem através da mudança de paradigma. Essa discussão já vinha provocando acalorados debates na primeira metade do século XX, estendendo-se, posteriormente.

Por paradigma Kuhn inicialmente compreende "as realizações científicas universalmente reconhecidas que, durante algum tempo, fornecem problemas e soluções modelares para uma comunidade de praticantes de uma ciência" (KUHN, 1998, p. 13). As descobertas científicas acontecem dentro de um contexto mais amplo, uma visão de mundo, que questiona, coloca em xeque o padrão até então aceito:

A descoberta começa com a consciência da anomalia, isto é, com o reconhecimento de que, de alguma maneira, a natureza violou expectativas paradigmáticas que governam a ciência normal [...]. Este trabalho somente se encerra quando a teoria do paradigma for ajustada [...] até que o cientista tenha aprendido a ver a natureza de um modo diferente. (KUHN, 1998, p. 78).

Segundo Luiz Bernardo Araújo (1996, p. 20), o debate atual mostra que os paradigmas são “incomensuráveis, razão pela qual não se pode falar em 'ciência' no singular e sim em 'espécies' ou 'tipos' de ciência”. E Kuhn percebida dois sentidos de paradigma: um sociológico e outro filosófico. Além "constelação de crenças, valores, técnicas, etc..., partilhadas pelos membros de uma comunidade determinada" (KUHN, 1998, p. 218), sentido sociológico, há o filosófico: "denota um tipo de elemento dessa constelação: as soluções concretas de quebra-cabeças que, empregadas como modelos ou exemplos, podem substituir regras explícitas como base para a solução dos restantes quebra-cabeças da ciência normal.” (KUHN, 1998, p. 218).

Nota-se que paradigma aparece aqui como novas soluções que vêm responder aos problemas ou lacunas deixadas pela concepção dada até aquele momento, nascidos de problemas concretos, oferecendo novas regras para a ciência. E essa visão é partilhada e reconhecida por uma comunidade de pesquisadores, ou seja, a comunidade científica representa um grupo que partilha um paradigma (KUHN, 1998, p. 219). 
Uma distinção importante é feita por Kuhn no desenvolvimento de seu conceito de paradigma: há dois tipos de ciência: a ciência normal e a extraordinária. Para ele, a ciência normal "significa a pesquisa firmemente baseada em uma ou mais realizações científicas passadas [...] reconhecidas durante algum tempo por alguma comunidade científica” (KUHN, 1998, p. 29). Por outro lado, a ciência extraordinária aparece quando surgem diversos indícios como "a proliferação de articulações concorrentes, a disposição de tentar qualquer coisa, a expressão de descontentamento explícito [...] [revelando] sintomas de uma transição da pesquisa normal para a extraordinária” (KUHN, 1998, p. 123). Tais manifestações indicam o surgimento de uma anomalia que "parece ser algo mais que um novo quebra-cabeças da ciência normal [...] [sendo] sinal de que se iniciou a transição para a crise e para a ciência extraordinária” (KUHN, 1998, p. 113-114); Aí começa a dinâmica de mudança: diante e como reação à anomalia, haverá continuidades e descontinuidades.

A partir dessas concepções, o que é importante reter? Primeiramente, o princípio de Eliade: “escala cria o fenômeno". Depois a crítica ao mito da neutralidade e da objetividade da ciência, assim como a visão de Popper que a ciência é um processo, tem limites e precisa de refutação e de validação contínua. Por fim, a ideia de paradigma de Kuhn, da existência da ciência normal e da extraordinária, da anomalia que questiona o sistema normal, e que a ciência é uma produção coletiva, de uma comunidade de pesquisadores.

\section{O PARADIGMA ECOLÓGICO E AS CONCEPÇÕES E ORIGENS DOS PENSAMENTOS PÓS-COLONIAIS, DESCOLONIAIS E DECOLONIAIS}

Depois de refletir sobre algumas concepções basilares da epistemologia, é o momento de apresentar ao debate dois paradigmas e horizontes de pensamento que têm impactado a discussão nas diversas áreas do conhecimento, incidindo também no campo dos Estudos de Religião: o paradigma ecológico e os pensamentos póscoloniais, descoloniais e decoloniais.

Apesar de que a produção das teorias pós-coloniais, dos estudos subalternos, do pensamento descolonial e decolonial, mas também do paradigma ecológico, terem acontecido numa cronologia muito próxima, falta encontrar suas proximidades, 
continuidades e descontinuidades, apesar das suas especificidades. Mas antes é preciso conhecer essas concepções para a seguir fazer esse trabalho crítico. Começase por tratar do paradigma ecológico e depois das teorias críticas ao colonialismo.

\subsection{O paradigma ecológico}

O paradigma ecológico, assim como as críticas colonialistas - pós-coloniais, estudos subalternos, pensamento descolonial e pós-colonial - nasce como crítica ao paradigma moderno, que prevaleceu até o início do século XX, o qual se produziu como reação ao dogmatismo clássico e medieval e ao essencialismo. A modernidade introduziu a subjetividade e o cogito, produzindo uma racionalidade cada vez mais dualista: "a divisão do mundo entre material e espiritual, a separação entre a natureza e a cultura, entre ser humano e mundo, razão e emoção, feminino e masculino, Deus e mundo e a atomização dos saberes científicos” (BOFF, 1995 p. 29).

Houve grande otimismo entre pensadores do século XVIII que estava fundado numa concepção empirista da verificabilidade das teorias, com "a ideia de que a credencial da ciência reside no fato de que seus enunciados observacionais podem ser verificados” (ARAÚJO, 1996, p. 18). Tal visão cede lugar à crise através do próprio desenvolvimento da ciência. Sempre haverá novos problemas que não terão resposta no esquema tradicional, como afirmava Heisenberg (1974, p. 230)1, cientista e um dos pais da física contemporânea.

Neste sentido, diversas concepções como a teoria da eletricidade, a teoria do calor, a eletrodinâmica, a cibernética, a teoria da relatividade e a teoria quântica, nascidas especialmente no campo da física, mas também na química e na biologia, foram criando uma nova cosmologia, gerando mudanças também nas ciências humanas, na filosofia, na ética, na teologia e nos Estudos de Religião. Esse processo contribuiu para colocar em xeque o paradigma científico moderno.

Há uma transformação no horizonte de compreensão do mundo, da matéria, das forças que interagem para manter o processo da vida e o desenvolvimento do cosmos, ou seja, o próprio paradigma hegemônico começa a mudar e a produzir nova

\footnotetext{
${ }^{1}$ Este autor afirma que, "Geralmente, no começo destas revoluções está um problema muito especial, estranhamente delimitado e que não há modo de solucionar dentro do marco tradicional”. (p. 230).
} 
compreensão da realidade. Mas tal mudança não é imediata e o novo paradigma convive com o antigo, questionando-o e sendo questionado por ele.

Entra em colapso o esquema da objetividade que produziu a razão instrumental-analítica, pois ele não é mais suficiente para a compreensão da complexidade dos fenômenos e de sua pretensão de legitimar os critérios de verdade. Assim, pensadores como Edgar Morin, a partir do final dos anos de 1960 e do início da década de 1970, oferecerão novas perspectivas e horizontes sobre a epistemologia, dentre eles o conhecido pensamento complexo. ${ }^{2}$

Essa visão analítica e instrumental de pensar e de agir das ciências modernas entra em crise: "passam para o primeiro plano as relações, que constituem a interdependência de todos os elementos do universo [...].” (OLIVEIRA, 1998, p. 281). O filósofo Manfredo Oliveira afirma que o modelo mecânico, da máquina, cede lugar para o "mundo atômico e subatômico [...] que [...] se disssolvem em ondas de probalidades e que, portanto, só podem ser entendidas como interconexões dinâmicas e entre processos" (OLIVEIRA, 1998, p. 280).3

Ainda segundo este autor, pode-se apresentar em três aspectos as principais mudanças ocorridas no paradigma das ciências atuais: da concepção estáticodeterminista para a processual-contingencial da realidade; de uma visão isolacionista para uma integracional de todos os seres; e de uma consideração materialista para uma concepção idealista-objetiva do universo. 4

Desta forma, ampliam-se significativamente os campos de pesquisa: a inteligência emocional, a biologia do conhecimento, a interatividade do homem e a máquina e os sistemas complexos. Teorias e conceitos bastante sedimentados são questionados. E um conceito moderno importante, como a ideia de subjetividade, fundamental nesse paradigma, se transforma: começa-se a pensar e agir com a consciência de que a terra, o planeta, o cosmos, os animais e vegetais são seres vivos,

2 Destaca-se, nesse sentido, Edgar Morin, sociólogo francês que teve suas ideias rejeitadas na década de 1970, sendo hoje considerado um dos três maiores pensadores vivos. Suas publicações, especialmente a partir do livro "O paradigma perdido" (MORIN, 1973) e "O método" (MORIN, 1977), se concentram na proposta do "Pensamento complexo", criando as bases para o despertar do "paradigma ecológico" ou do "pensamento eco-sistêmico" (MORAES, 2004).

3 Para uma mais completa abordagem desta visão neste autor ver ANJOS, 1997, p. 21-39, no artigo de Manfredo Oliveira: "A mudança de paradigma nas ciências contemporâneas".

4 Na conclusão do seu texto, Manfredo Oliveira (1997, p. 39) afirma: "pode-se interpretar o processo evolutivo, que constitui o universo enquanto tal, a partir da visão das ciências contemporâneas, como as diferentes etapas do processo de desdobramento do espírito que vem a si, toma consciência de si em suas diferentes figuras até chegar à consciência plena de todo o processo cosmogênico no espírito humano".

INTERAÇõES, Belo Horizonte, Brasil, v. 13. n. 23, p.94-114, jan./jul.2018

ISSN 1983-2478 
portanto, têm subjetividade, têm direitos (ACOSTA, 2010; ACOSTA; MARTINEZ, 2011; HOUTART, 2011). Quebra-se o reducionismo antropocêntrico, defende-se a dignidade de todos os seres, rompe-se com o antropocentrismo que só qualificava aquilo que se referia ao humano, admitindo apenas certa deferência às coisas e seres na medida em que poderiam ser utilizados e manipulados pelo ser humano.

Todo esse processo emerge como fruto da percepção, mas também da pesquisa científica. Percebe-se que tudo interage com tudo, o tempo todo. Os estudos de Ilya Prigogine5 sobre a irreversibilidade mostram que a evolução caminha numa perspectiva de complexificação: "a seta do tempo e a linha da evolução vão no sentido de criar cada vez mais complexidades auto-organizadas, diversidades e inter-retrorelacionamentos”. (BOFF, 1998, p. 45). E a física deu enorme contribuição para isso ao descobrir as ínfimas partículas e a própria impossibilidade de separar, como antes, matéria e energia. De uma concepção dualista passa-se para uma visão dialética, ou mais que dialética, circular, dialógica, complexa, interativa: tudo carrega informação, tudo tem história, dos átomos, das estrelas aos seres mais ínfimos como os protozoários unicelulares, as amebas.

Essa nova cosmologia nasce também da interação com os estudos da biologia que revelam, segundo Leonardo Boff, algumas características: a não-linearidade (tudo é rede de relações que não se limitam a causa-efeito); a dinâmica cíclica (adaptação e equilíbrio é um processo constante, em movimento, num processo de crescimento cíclico, incluindo a morte que gera vida); sistema estruturado (os sistemas se subdividem e guardam interação entre si, cada um fazendo parte de um organismo maior); autonomia e integração (há autonomia e integração entre os sistemas); auto-organização e criatividade (cada sistema complexo pode estruturarse criativamente, num contínuo processo evolutivo). (BOFF, 1993, p. 43-44). Tudo isto revela a vida presente nesse superorganismo que é a Terra. Nesta perspectiva, o conceito de ecologia vai superando seu nicho "regional" e se torna universal, um novo paradigma que detém a grande força "mobilizadora do futuro milênio" (BOFF, 1993, p. 25).

Tudo isto não se fez e não está acontecendo sem grande crise nos modelos estabelecidos. É do confronto com o paradigma moderno, com sua razão

\footnotetext{
5 Ilya Prigogine, químico (Universidade de Bruxelas e Universidade de Austin, Texas), ganhou o prêmio Nobel em 1977 e se dedicou a investigar a questão do tempo. Faleceu em 2003. Ver: PRIGOGINE, 1990; 1996; e PRIGOGINE; STENGERS, 1990.
} 
instrumental-analítica e da ameaça que este gera de colapso da própria da sobrevivência humana, de seu futuro, que vai se forjando novo horizonte de compreensão e, daí, novo agir, e também nova Ética.

\subsection{Visão panorâmica da origem e das principais concepções das teorias pós- coloniais, dos estudos subalternos e do pensamento descolonial e decolonial}

Mesmo correndo o risco da simplificação, é necessário apresentar uma visão ampla da origem das teorias críticas ao colonialismo e suas principais ideias.

No contexto de um longo percurso teórico, até os anos de 1980, no âmbito de estudos culturais e literários, tanto na Inglaterra quanto nos Estados Unidos, surge o pensamento pós-colonial, como crítica e luta ao colonialismo. $\mathrm{Na}$ afirmação das diferenças, a base crítica se refere aos binarismos, essencialismos, androcentrismos, patriarcalismos, universalismos, ao eurocentrismo e à "idolatria da identidade" (Catherine Keller). Nesses estudos culturais, destaca-se o Centre for Contemporary Cultural Studies (CCCS), com início nos anos de 1960 na Universidade de Birmingham, na Inglaterra, e um dos expoentes é o jamaicano Stuart Hall, ao lado dos fundadores Richard Hoggart e Raymond Williams. Nesse grupo cria-se mais tarde (1974) o Women's Studies Group, introduzindo no debate as questões de gênero. Além disso, já se discutia a perspectiva racial por Hall (2002), trabalhada a

partir da sua condição de autor diaspórico. Outras referências importantes e conhecidas dos brasileiros são o indiano Homi Bhabha (1998) e o inglês Paul Gilroy (2002). Pode-se somar a essas influências a visão multiculturalista que surge, basicamente em solo norte-americano, entre os anos de 1970 e 1980. Nessa perspectiva, participa mais tarde (1994) do debate sobre o multiculturalismo o canadense Charles Taylor (1998), colocando a sua questão da "política do reconhecimento" na formação da identidade.

Todavia, não se pode esquecer que, no contexto dos processos libertários de muitos países, entre 1940 e 1950, na Ásia e na África, surgem diversos pensadores como Césaire, com o livro Discurso sobre o colonialismo (1950), Memmi, com seu livro Retrato do colonizado precedido de retrato de colonizador (1957), Fanon e o seu Os condenados da terra (1961). Tais livros influenciaram muitos brasileiros, como Paulo Freire (1970, p. 52). Mais tarde outro intelectual como Edward Said 
escreve Orientalismo: o Oriente como invenção do Ocidente (1978). Todos esses autores terão grande influência nos estudos pós-coloniais. Deve-se observar que esse “pós”, do pós-colonialismo, não tem o sentido temporal, de "depois", mas quer destacar a tarefa de enfrentamento e superação das colonialidades. Essas concepções emergiram no contexto da crítica e diálogo com o pós-estruturalismo, o pósmarxismo, o desconstrutivismo e a visão pós-moderna, e não há aqui espaço para mostrar essas relações.

Ainda nas origens do pensamento pós-colonial encontram-se também os Estudos Subalternos, nascentes na década de 1970, na Índia, com Rajajit Guha. Dissidente da visão marxista, Guha, juntamente com os indianos Partha Chatterjee, Dipesh Chakrabarty e Gayatri Chakrabarty Spivak, formará a “tríade sagrada” do póscolonialismo (BALLESTRIN, 2013). Dentre esses autores, especialmente Spivak, em seu livro Pode o subalterno falar? (2010), assume uma crítica a esses estudos e a seus intelectuais. Segundo a autora, não se pode ocupar o lugar de fala do colonizado, pois isso representaria um ato de discurso hegemônico. Na visão de Ballestrin (2013, p. 93), o projeto de Boaventura Santos, de uma Universidade Popular, visa "romper com a lógica de intermediação de saberes e práticas entre militantes e intelectuaismilitantes”.

Inspirados nos Estudos Subalternos ${ }^{6}$ asiático, funda-se no início dos anos de 1990 o Grupo Latino-americano dos Estudos Subalternos, nos Estados Unidos. Participa desse coletivo o peruano Anibal Quijano, pesquisador da teoria da dependência e que trabalhava com I. Wallerstein, desenvolvedor do conceito de “sistema-mundo". O Manifesto do Grupo será publicado em 1993. A posição de Quijano mostra a relação entre o colonialismo e a modernidade e sua racionalidade, com sua presença contínua na cultura. E questiona o processo de conhecimento e sua epistemologia que necessita de "descolonización”.

Outro pesquisador importante do grupo, que já começa questionando as bases desses estudos subalternos latino-americanos, é o argentino Walter Mignolo que “pensa que as teses de Ranajit Guha, Gayatri Spivak, Homi Bhabha e outros teóricos indianos não deveriam ser assumidas e transferidas sem mais para uma análise do caso latino-americano”. (CASTRO-GÓMEZ; MENDIETA, 1998, p. 17). É preciso uma

\footnotetext{
6 Ballestrin (2013, p. 93) explica que o "termo 'subalterno' fora tomado emprestado de Antonio Gramsci e entendido como classe ou grupo desagregado e episódico que tem uma tendência histórica a uma unificação sempre provisória pela obliteração das classes dominantes.”
} 
postura crítica, com concepções, conceitos e categorizações que surjam a partir da América Latina. Essas e outras críticas, como o rompimento com a episteme do Norte, levaram à dissolução desse grupo sobre Estudos Subalternos em 1998 e, daí, nasce o Grupo Modernidad/Colonialidad - M/C. Porém, a maioria dos membros não mudou. Pode-se indicar uma diversidade de pesquisadores no M/C: W. Mignolo (um dos principais fundadores), A. Quijano, E. Dussel, E. Lander, K. Santiago, R. Grosfoguel, A. Lao-Montes, Sylvia Wynters, N. Maldonado-Torres, S. Castro-Gómez, Catherine Walsh, A. Escobar, F. Coronil, E. Mendieta, Ana. M. Cervantes-Rodorigues, I. Wallerstein, Zulma Palermo, Boaventura Souza Santos, dentre outros.7 Ballestrin (2013, p. 98) identifica as nacionalidades dos membros do M/C, e são diversas: colombiana, argentina, peruana, caribenha, chilena, venezuelana, estadounidense, porto-riquenha, portuguesa, além de outras, mas não há brasileiros, pelo que verificou até àquele momento. ${ }^{8}$ Com esse grupo nasce importante parceria entre as universidades Pontifícia Universidade Javeriana (Bogotá, Colômbia) e as norteamericanas Duke University, University of North Carolina e a Universidade Andina Simón Bolivar (La paz, Bolívia).

Os estudos do $\mathrm{M} / \mathrm{C}$, demarcados com os conceitos de colonialidade e decolonialidade, partem da crítica à ideia de que com o fim da colonização história, com a independência política ( $1^{\mathrm{a}}$. descolonização), haveria "a" descolonização e se viveria num período pós-colonizado. Supera também a concepção latino-americana da "teoria da dependência". Para o M/C, a divisão internacional do trabalho, a classificação e hierarquização étnico-racial dos povos, (nascida na colonização da América), bem como entre centro e periferia do sistema, foram produzidas desde o final do século XV pela expansão europeia. Segundo Castro-Gómes e Grosfoguel (2007, p. 13), o processo se complexificou e passou-se do "colonialismo modermo para a atual colonialidade global”. Questiona-se, assim, o “mito da descolonização" e também a visão da pós-modernidade, que viveríamos a caminho de uma sociedade

\footnotetext{
7 Para conhecer um pouco do trabalho desse Grupo é importante ler El giro decolonial (CASTROGÓMEZ; GROSFOGUEL, 2007).

8 Darcy Ribeiro é citado com antropólogo brasileiro que no início dos anos de 1970 mostrava que o império "marcha hacia las colonias con armas, libros, conceptos y pre-conceptos". (MIGNOLO, 2010, p. 10).
} 
fora da colonialidade. 9 Por isso, esses autores, a partir da posição decolonial $\left(2^{\mathrm{a}}\right.$. descolonização), dizem que "el capitalismo global contemporâneo resignifica, en un formatado posmoderno, las exlusiones provocadas pelas jerarquias epistêmicas, espirituales, raciales/étnicas y de genero/sexualidade desplegadas por la modernidade”. (CASTRO-GÓMES; GROSFOGUEL, 2007, p. 14).

Há diferenças fundamentais entre essas posições do M/C e os Estudos póscoloniais, inclusive dos Subalternos. Amparados no conceito "sistema-mundo" (Wallerstein e Quijano), o M/C critica-lhes a "ênfase" no discurso colonial e mostra que o "sistema-mundo seña-la la interminable e incesante acumulación de capital para a escala mundial como la determinación en 'última instancia'." (CASTROGÓMES; GROSFOGUEL, 2007, p. 15). Também há a crítica sobre o destaque que os pós-coloniais dão à "agencia cultural de los sujetos", pois o M/C defende a ênfase nas estruturas econômicas. Há grande debate sobre essa questão, mas que não será possível abordar aqui. (BAPTISTA, 2016, p. 498).

Uma observação importante: não se encontra nos dicionários os termos “descolonial” e nem "decolonial”, apenas o verbo “descolonizar". O neologismo decolonial, criado pelo Grupo M/C, sem o "s", quer demarcar a diferença entre a proposta desse Grupo e "a ideia histórica de descolonização, via libertação nacional durante a Guerra Fria”. (BALLESTRIN, 2013, p. 108).

Com essa panorâmica sobre o paradigma ecológico e as teorias críticas às diversas colonialidades pode-se, a seguir, discutir sobre as suas articulações e os Estudos de Religião.

\section{AS EPISTEMOLOGIAS PÓS-COLONIAIS, DESCOLONIAIS, DECOLONIAIS E ECOLÓGICAS E OS DESAFIOS PARA OS ESTUDOS DE RELIGIÃO}

Tudo o que se apresentou até aqui mostra, fundamentalmente, que as novas epistemologias questionam o paradigma moderno, desmascaram os interesses coloniais presentes nele e buscam pensar a partir de outra lógica, ou seja, que a ciência é uma produção histórica, contextual e coletiva e deve servir à verdade e ao interesse público, à qualidade de vida para todas e todos, incluindo os seres vivos e

\footnotetext{
9 O colonialismo refere-se à dominação econômica, política, militar, administrativa etc. A colonialidade é a permanência da dominação mesmo depois da libertação colonial, como forma de poder, através do saber e do ser.
} 
não vivos, começando por quebrar as estruturas dominadoras, opressoras e destruidoras das condições socioambientais, em grande parte produzidas a partir de interesses econômicos e políticos.

Recuperando a ideia epistemologia inicial de Eliade, que "a escala cria o fenômeno”, percebe-se que a partição da ciência, sua ultra especialização (Morin), reduz a percepção do objeto, sob a pretensão ilusória de garantir a objetividade (Popper). Conhece-se partes, recorta-se, delimita-se o objeto ao mínimo detalhe, para se "garantir" alguma certeza, mas falta o olhar de conjunto. E a realidade mostra esse problema, essa anomalia. A realidade é complexa e não pode ser reduzida aos recortes. Temos que pensar complexamente a realidade, e a partir de incerteza (Heisenberg). E a própria ciência deve ser pensada no plural (ARAÚJO, 1996).

A ciência normal não dá conta dessa complexidade, por isso precisa-se de caminhos alternativos, novos paradigmas, ciências extraordinárias, trabalhadas coletivamente (Kuhn), mesmo que com olhares particulares e localizados. Por exemplo, as dissertações e teses são pesquisas individuais, justificáveis, mas não se criou ainda a possibilidade de pesquisas assim coletivas, com o mesmo objeto, mas com diversos olhares sobre eles, uma comunidade de pesquisadores aprofundando-se nas múltiplas faces do objeto, do fenômeno. Se é utilizada a mesma escala, essa medida única determina o olhar sobre o fenômeno, que "aparece" condicionado pela escala, por esse olhar. É preciso de descolonizar ou “ecologizar” essas epistemologias.

Os objetos dos Estudos de Religião, como em todos os campos de pesquisa, são muito variados e as formas de abordá-los são numerosas. Essa mesma área, que no Brasil recebe diversos nomes como Ciência(s) da(s) Religião(ões), revela-se multidisciplinar e com sua epistemologia em construção. Não é tarefa fácil trabalhar de forma inter, multi, poli e transdisciplinar. Exige grande preparação dos pesquisadores e muita prática, além da capacidade de trabalho em equipe. Será que essa área de Estudos de Religião tem realizado isso? Será que seus Grupos de Pesquisa trabalham assim? Talvez muito pouco. Não há dados sobre isso. Geralmente, escolhe-se uma escala, faz-se um recorte, por exemplo sociológico, com alguns aportes de teóricos desse campo, e analisa-se o objeto, responde-se a algumas hipóteses, defende-se uma tese. Pode-se dizer que assim se faz ciência? Não! Talvez, sim, no padrão aceito e reconhecido. Mas de forma crítica e anedótica pode-se dizer que com isso se conhece "tudo de nada" ou, utilizando-se de uma metáfora, 
especializa-se em "ponto", mas tal conhecimento não ajuda a compreender a "reta", que por definição é um conjunto de pontos. Porém, um grupo de pesquisadores poderia, com o mesmo objeto, abordá-lo com diversas escalas, ampliar de forma mais profunda os conhecimentos desse fenômeno, além de que o trabalho em equipe propiciaria em todo o processo a discussão crítica, o que seria difícil de fazer uma única pessoa, pelas limitações próprias de tempo e de horizonte.

Nesse sentido, considera-se que as epistemologias discutidas neste artigo têm diversas proximidades e trazem desafios e questionamentos importantes para os Estudos de Religião.

Primeiramente, seria fundamental reconhecer que as colonialidades do poder, do saber, do ser e da natureza são colonialidades que determinam o ver, o fazer, o pensar, o ouvir e o sentir, ou seja, determinam também o pesquisar. Isso atinge a todas e todos, especialmente nesse campo controverso que é a religião, pois o crer ou o não crer estão presentes na pessoa do(s) pesquisador(es) e deve ser considerado no processo.

Como área multidisciplinar, os Estudos de Religião devem reconhecer também a diversidade epistemológica, ainda mais diante das sociedades, tradições e culturas, uma "pluralidade conflitual de saberes" (SANTOS, 2005, p. 21). Contraditoriamente, dentro dessa própria área de Estudos há quem exclua a teologia desse campo, reduzindo-o às ciências empíricas. É preciso, deve-se repetir, ecologizar e descolonizar essa visão. ${ }^{10}$

Por isso, nos Estudos de Religião seria importante superar a visão de certa "ciência" que tem a pretensão de definir a validade e cientificidade do conhecimento e que produz verdadeiro "epistemicídio" e a "destruição criadora”. Para Souza Santos (2005, p. 22) isso representa a "morte de conhecimentos alternativos" e a “subalternização dos grupos sociais”. A sabedoria das tradições e espiritualidades não pode deixar de ser considerada. Vale lembrar Durkheim que defendia a ideia da origem social e religiosa das principais categorias e representações sociais e das ciências:

${ }^{10}$ Sobre a discussão entre teologia e pensamento decolonial ver CUNHA, 2017.

INTERAÇõES, Belo Horizonte, Brasil, v. 13. n. 23, p.94-114, jan./jul.2018 ISSN 1983-2478 
Os primeiros sistemas de representações que o homem produziu no mundo e de si próprio são de origem religiosa. [...] Se a filosofia e as ciências nasceram da religião é porque a própria religião, no princípio, fazia às vezes de ciência e de filosofia. (DURKHEIM, 1989, p. 37).

Há a necessidade de uma "desobediência epistêmica" e de se produzir conhecimento com os pés e a cabeça a partir do lugar do colonizado, o que representa uma atitude política, de uma "nova identidade em política", questionando o paradigma moderno e eurocentrado, que são definidos a partir de certas teorias políticas e econômicas. (MIGNOLO, 2008). Isso não significa jogar fora os conhecimentos produzidos nesses grandes centros de saber e poder. Porém, eles devem ser analisados criticamente e deve-se dar espaço também para novos conhecimentos emergentes em outros espaços, especialmente aqueles da periferia. É da interação crítica entre saberes e sabedorias que se pode aproximar de um ideal de verdade, sempre a ser perseguido, testado, validado e questionado. Um exemplo no campo de Estudos da Religião: a Teologia da Libertação foi produzida na América Latina, mas ela não seria possível sem o Concílio Vaticano II, Medellín e com seus teólogos tendo estudado no primeiro mundo.

Os problemas que surgem a cada dia para a epistemologia dos Estudos de Religião devem ser enfrentados também a partir da visão de paradigma de T. Kuhn. A solução desses "quebra-cabeça", dessas anomalias, é um debate dentro das ciências da religião, mas também de "abertura de diálogo entre formas de conhecimento e de saber" que possibilitem a emergência de uma "ecologia de saberes", da diversidade de saberes, mas que geralmente não são reconhecidos e que nem sequer se admite sua existência (SANTOS, MENEZES, 2009, p. 453).

Os Estudos de Religião, desafiados pelas epistemologias do paradigma ecológico e daquelas críticas às colonialidades, podem exercitar formas criativas de fazer ciência, enfrentando, através da qualidade de suas produções, a desconfiança que outras ciências têm das "Ciências da Religião", as críticas que não se faz ciência nesse campo. E a qualidade e fundamentação teórica é a base desse enfrentamento, entrando no debate duro da teoria da ciência. Esse campo de pesquisa, em processo de construção, tem muito a caminhar no debate de sua epistemologia plural. E, pela própria natureza de sua área, deve considerar, como já se afirmou, o diálogo com os 
saberes religiosos, reconhecendo-lhes a dignidade de conhecimento, bem como o desafio de produzir pesquisas coletivamente.

\section{CONCLUSÃO}

Na epígrafe deste texto evocou-se a música Invisível (2017), pois considera-se que os Estudos de Religião ainda sofrem de invisibilidade no campo das ciências. Um conceituado pesquisador de sociologia da religião, que se considera pertencente e atuante no campo das Ciências da Religião, recebeu há alguns anos, de outro colega que pesquisava sobre as mesmas questões, mas filiado à Sociologia, a crítica que a área de Ciências da Religião não era ciência.

Porém, a invisibilidade mais grave diz respeito ao processo da colonialidade, que exclui, discrimina, oprime e mata. Isso acontece nas relações de poder, de saber, do ser e da natureza. Há tradições religiosas que continuam perseguidas e proibidas de viver e expressar suas crenças. Existem milhões de mulheres e homens, pessoas das comunidades LGBT, jovens, idosos, crianças, agredidas pela sua condição de religiosa, cor da pele, lugar onde mora, opção sexual, condição de gênero, situação socioeconômica e tantas mais formas de discriminação. Como afirma a letra, é preciso mudar o olhar, ver e agir de outras formas: "Há maneiras de ver, maneira de ser, Maneira de crer, maneira de ver.” E os Estudos de Religião podem oferecer sua reflexão crítica sobre isso.

As teorias e as epistemologias do paradigma ecológico e pós-coloniais tiveram e têm o mérito de desocultar os jogos de poder, os interesses e as exclusões epistêmicas, gerando o desafio da criatividade, da ecologia dos saberes e da desobediência epistemológica. Nesse sentido, os Estudos de Religião ganham horizontes importantes que podem contribuir para avançar esse campo de conhecimento que, em construção das teorias das suas ciências, ainda dá seus primeiros passos nas territorialidades dos novos mundos.

A qualidade teórica e da pesquisa, especialmente se há um trabalho coletivo nos Grupos e Linhas de Pesquisa afins, que precisam se encontrar nos eventos da área ou eventos temáticos sobre a pesquisa do campo da religião, para discutir sobre teoria e fundamentos epistemológicos, planejar e divulgar pesquisas, será o caminho 
para que haja visibilidade e para dar passos mais largos de cientificidade dos Estudos de Religião.

\section{REFERÊNCIAS}

ACOSTA, Alberto. Hacia la Declaración Universal de los Derechos de la Naturaleza Reflexiones para la acción. Revista AFESE, Quito, v. 54, n. 54, p. 11-32, 2010. Disponível em: <http://www.revistaafese.org/ojsAfese/index.php/afese/article/view/433>. Acesso em: 10 set. 2017.

ACOSTA, Alberto; MARTÍNEZ, Esperanza (Comp.). La naturaleza con derechos: de la Filosofía a la Política. Quito: Ediciones Abya-Yala, 2011.

ANJOS, Márcio Fabri dos. Teologia aberta ao futuro. São Paulo: Loyola, 1997.

ARAÚJO, Luiz Bernardo L. Considerações sobre o termo "paradigma”. In: ANJOS, Márcio Fabri dos. Teologia e novos paradigmas. São Paulo: Loyola, 1996. p. 1533.

BALLESTRIN, Luciana. América Latina e o giro decolonial. Revista Brasileira de Ciência Política, Brasília, n. 11, p. 89-117, maio-agosto 2013. Disponível em: <http://www.scielo.br/scielo.php?script=sci_arttext\&pid=So10333522013000200004>. Acesso em: 16 maio 2016.

BAPTISTA, Paulo Agostinho N. Pensamento decolonial, teologias pós-coloniais e Teologia da Libertação. Perspectiva Teológica, Belo Horizonte, v. 48, n. 3, p. 491517, set./dez. 2016. Disponível em:

<http://faje.edu.br/periodicos/index.php/perspectiva/article/view/370o/o >. Acesso em: 10 set. 2018.

BHABHA, Homi K. O local da cultura. Belo Horizonte: Ed. UFMG, 1998.

BOFF, Leonardo. Dignitas Terrae. Ecoloiga: grito da terra, gripo dos pobres. São Paulo: Ática, 1995.

BOFF, Leonardo. Ecologia, mundialização, espiritualidade: a emergência de um novo paradigma. São Paulo: Ática, 1993.

BOFF, Leonardo. Nova era: a civilização planetária, desafios à sociedade e ao cristianismo. 3 ed. São Paulo: Ática, 1998.

CASTRO-GÓMEZ, Santiago; GROSFOGUEL, Ramón. El giro decolonial: reflexiones para una diversidad epistémica más allá del capitalismo global. Bogotá: Siglo del Hombre, 2007. Disponível em: 
<http://www.unsa.edu.ar/histocat/hamoderna/grosfoguelcastrogomez.pdf >. Acesso em: 12 jun. 2016.

CASTRO-GÓMEZ, Santiago; MENDIETA, Eduardo. Teorías sin disciplina; latinoamericanismo, poscolonialidad y globalización en debate. México: Miguel Ángel Porrúa, 1998. Disponível em:

$<$ http://people.duke.edu/ wmignolo/InteractiveCV/Publications/Teoriassindiscipli na.pdf $>$. Acesso em: 20 maio 2016.

CESAIRE, Áimé. Discurso sobre o colonialismo. Lisboa: Livraria Sá da Costa Editora, 1978. [Original: Discours sur le colonialisme. Paris: Reclaim, 1950].

CUNHA, Carlos. Provocações decoloniais à Teologia cristã. São Paulo: Edições Terceira Via, 2017.

DURKHEIM, Émile. As formas elementares da vida religiosa. 2. ed. São Paulo: Paulus, 1998.

ELIADE, Mircea. Tratado de história das religiões. São Paulo: Martins Fontes, 1993.

FANON, Frantz. Os condenados da terra. Rio de Janeiro: Civilização Brasileira, 1968. [Original: Les Damnés de la Terre. Paris: François Maspero, 1961].

FREIRE, Paulo. Pedadogia dos oprimidos. São Paulo: Paz e Terra, 1970.

GILROY, Paul. O Atlântico Negro: modernidade e dupla consciência. Rio de Janeiro: 34/Universidade Cândido Mendes, 2002.

HALL, Stuart. Da diáspora - identidades e mediações. Belo Horizonte: Editora UFMG, 2002.

HEISENBERG, Werner. Mas alla de la física. Madrid: Biblioteca de Autores Cristianos, 1974 .

HOUTART, François. El concepto de sumak kawsai (buen vivir) y su correspondencia con el bien común de la humanidade. ALAI, América Latina en Movimiento, 02 jun. 2011. Disponível em:

<http://www.dhl.hegoa.ehu.es/ficheros/oooo/o738/15._El_concepto_de_sumak_k awsai.pdf $>$. Acesso em 10 set. 2017.

JAPIASSÚ, Hilton. O mito da neutralidade científica. Rio de Janeiro: Imago, 1975 .

KUHN, Thomas. A estrutura das revoluções científicas. 5 ed. São Paulo: Perspectiva, 1998.

KUHN, Thomas. The Structure os Scientific Revolutions. Chicago: The University of Chigado Press, 1962. 
KÜNG, Hans. Teologia a caminho: fundamentação para o diálogo ecumênico. São Paulo: Paulinas, 1999.

LAKATOS, Imre. Criticism and the methology of scientific research programmes. Proceedings of Aristotelian Society, Oxford, v. 69, n. 1, p. 149-186, June 1969.

MEMMI, Albert. Retrato do colonizado precedido pelo retrato do colonizador. 2. ed. Rio de Janeiro: Paz e Terra, 1977.

[Original: Portrait du colonisé, précédé par Portrait du colonisateur. Paris: Editions Buchet/Chastel, 1957].

MIGNOLO, Walter. Desobediência epistêmica: a opção descolonial e o significado de identidade em política. Cadernos de Letras da UFF, Rio de Janeiro, n. 34, p. 287324, 2008. Disponível em:

<http://www.uff.br/cadernosdeletrasuff/34/artigo18.pdf>. Acesso em: 15 jul. 2016.

MIGNOLO, Walter. Desobediencia epistémica: retórica de la modernidad, lógica de la colonialidad e gramática de la descolonialidad. Buenos Aires: Ediciones del Signo, 2010. Disponível em: < https://antropologiadeoutraforma.files.wordpress.com/2013/04/mignolo-walterdesobediencia-epistc3a9mica-buenos-aires-ediciones-del-signo-2010.pdf $>$. Acesso em: 13 jun. 2016.

MORAES, Maria Cândida. Pensamento eco-sistêmico. Petrópolis: Vozes, 2004.

MORIN. Edgar. O método I - A natureza da natureza. 2. ed. Lisboa: Publicações Europa-América, 1977.

MORIN. Edgar. O paradigma perdido: a natureza humana. 4. ed. Lisboa: Publicações Europa-América, 1973.

OLIVEIRA Manfredo A. Ampliação do sentido de libertação. Perspectiva Teológica, Belo Horizonte, v. 30, n. 81, p. 273-284, jan. 1998. Disponível em: <http://www.faje.edu.br/periodicos/index.php/perspectiva/article/view/678/1103>. Acesso em: 01 jun. 2018.

OLIVEIRA, Manfredo A. A mudança de paradigmas nas ciências contemporâneas. In: ANJOS, Márcio Fabri dos. Teologia aberta ao futuro. São Paulo: Loyola, 1997. p. 21-29.

OLIVEIRA, Marcos Barbosa de. Sobre o problema da demarcação. Trans/Form/Ação, São Paulo, n. 5, p. 85-101, 1982.

POPPER, Karl. A lógica da pesquisa científica. São Paulo: Cultrix, 1972.

POPPER, Karl. Conjectures and Refutations. Londres: Routledge \& Kegan Paul, 1963. 
PRIGOGINE, I.. A nova aliança: metamorfose da ciência. Brasília: Universidade de Brasília, 1990.

PRIGOGINE, I.. O fim da certeza: tempo, caos e as leis da natureza. São Paulo: UNESP, 1996.

PRIGOGINE, I..; I. STENGERS,; I.. Entre o tempo e a eternidade. Lisboa: Gradiva, 1990.

SAID, Edward W. Orientalismo: o Oriente como invenção do Ocidente. São Paulo: Companhia das Letras, 2007. [Original: London: Routledge \& Kegan Paul Ltd., 1978].

SANTOS, Boaventura Sousa; MENESES, Maria Paula (Org.). Epistemologias do sul. Coimbra: Edições Almedina, 2009.

SANTOS, Boaventura de Souza; MENESES, Maria Paula; NUNES, João Arriscado. Para ampliar o cânone da ciência: a diversidade epistemológica do mundo IN: SANTOS, Boaventura de Souza (Org.). Semear outras soluções: os caminhos da biodiversidade e dos conhecimentos rivais. Rio de Janeiro: Civilização Brasileira, 2005. p. 21-121.

SPIVAK, Gayatri C. Pode o subalterno falar? Belo Horizonte: Editora UFMG, 2010.

TAYLOR, Charles. A política do reconhecimento. In: TAYLOR, Charles (Org.).

Multiculturalismo. Lisboa: Instituto Piaget, 1998. p. 44-64.

TOULMIN, Stephen. Kritik der Kollektiven Vernunft. Frankfurt: Suhrkamps, 1978. 